\section{NITRACIDOMYCINS A AND B, NEW ENTEROMYCIN-GROUP ANTIBIOTICS}

Communications to the Editor
Sir:

In the course of our screening program for new antibiotics with spheroplast formation, nitracidomycins A (1a) and B (1) $)^{12}$ were obtained from the culture filtrate of a streptomycete. They were characterized and shown to have a nitronic acid and an 4-amino-3hydroxy acid moiety in their structures; they both had moderate activities against Grampositive bacteria and some species of Gramnegative bacteria, such as Bacteroides fragilis. In this report, the production, isolation, physicochemical properties, structures and biological properties of $\mathbf{1 a}$ and $\mathbf{1 b}$ are reported.

A streptomycete which produced $\mathbf{1 a}$ and $\mathbf{1 b}$ was isolated from the soil sample collected at Ogose, Saitama Prefecture, Japan, and identified as Streptomyces viridochromogenes SANK 60784
(FERM P-7582). Fermentation of $S$. viridochromogenes SANK 60784 was carried out in a 600-liter fermentor, containing 300 liters of medium composed of glucose $3.0 \%$, pressed yeast $1.0 \%$, soybean meal $3.0 \%, \mathrm{CaCO}_{3} 0.4 \%$, $\mathrm{MgSO}_{4} \cdot 7 \mathrm{H}_{2} \mathrm{O} \quad 0.2 \%$, and $\mathrm{CB}-4420.01 \%(\mathrm{pH}$ 7.0 before sterilization), at $28^{\circ} \mathrm{C}$ for 73 hours with agitation of $220 \mathrm{rpm}$ and aeration of 300 liters/minute.

The culture filtarate (280 liters) was adjusted to $\mathrm{pH} 2.0$ and the antibiotics were extracted with 300 liters of EtOAc. The active principles in the organic layer were extracted further with 290 liters of diluted alkaline solution $(\mathrm{pH} 10)$. The

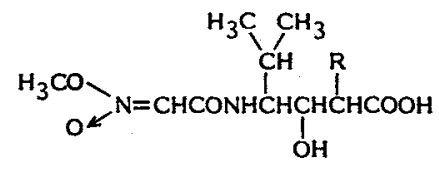

1a $\mathrm{R}=\mathrm{CH}_{3}$

ib $\mathrm{R}=\mathrm{CH}_{2} \mathrm{CH}_{3}$

Fig. 1. IR spectrum of nitracidomycin $\mathrm{A}(\mathrm{KBr})$.

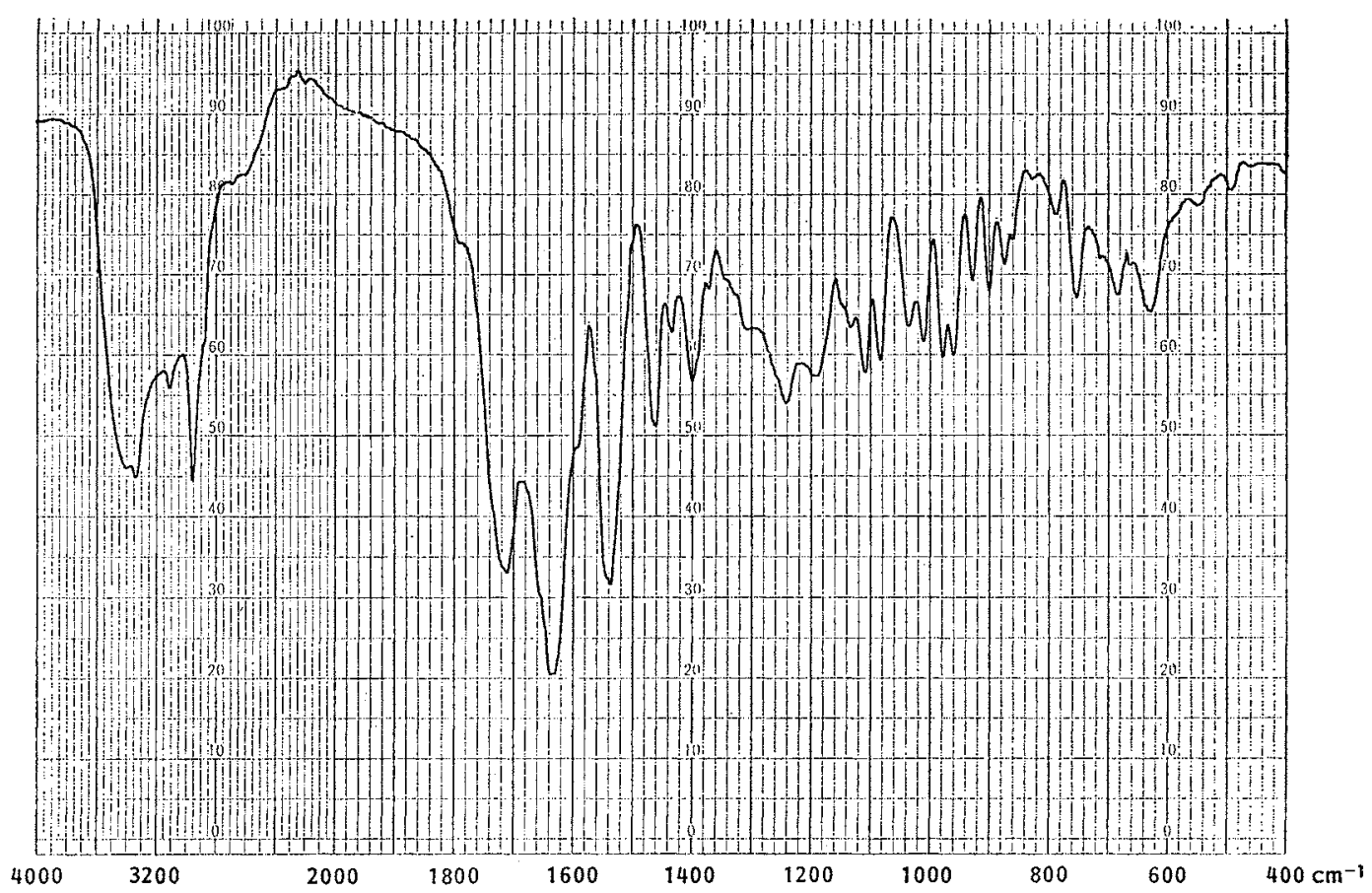


Fig. 2. ${ }^{1} \mathrm{H}$ NMR spectrum of nitracidomycin $\mathrm{A}$ in $\mathrm{CDCl}_{3}(270 \mathrm{MHz})$.

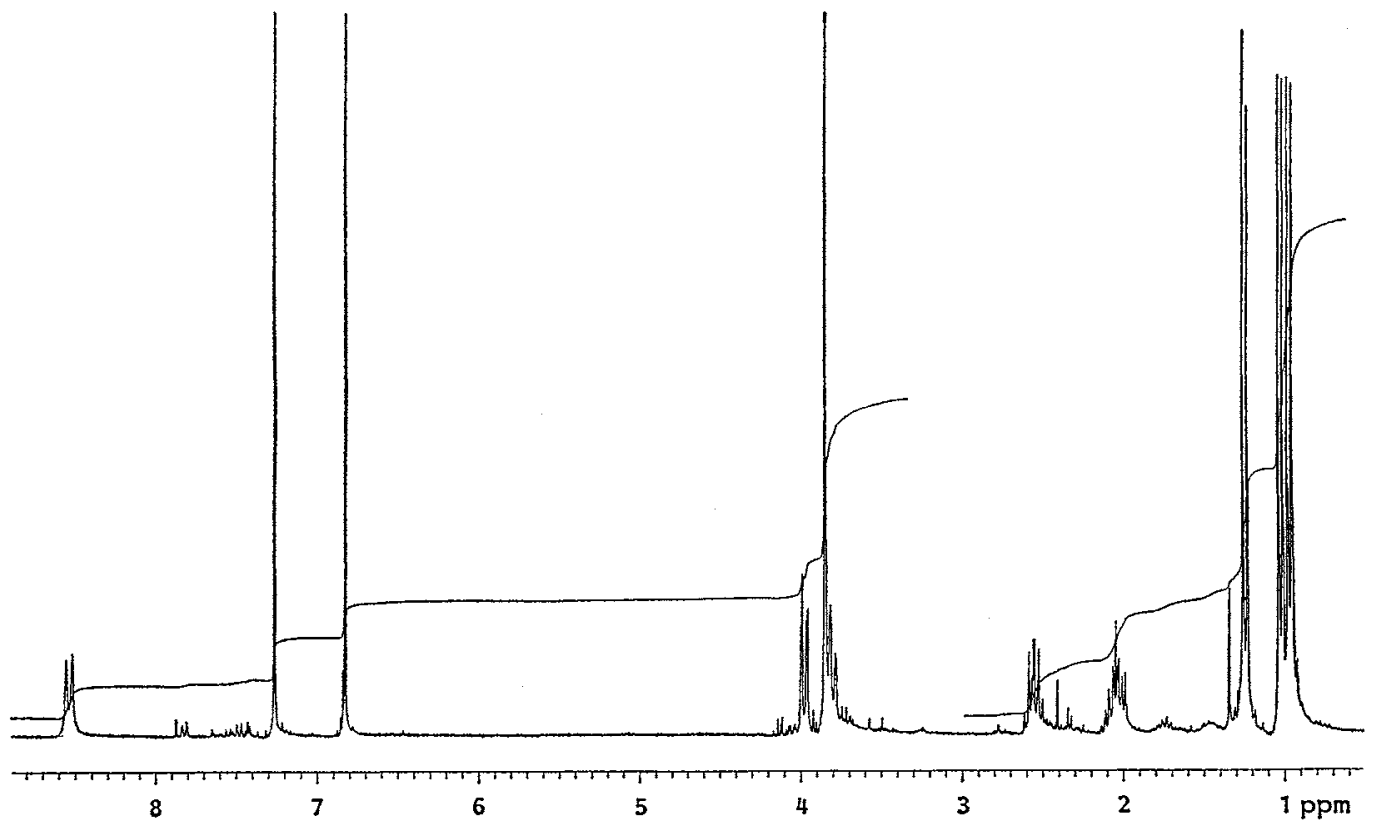

Fig. 3. ${ }^{13} \mathrm{C}$ NMR spestrum of aitelidon $y$ in $\mathrm{A}$ in $\mathrm{CDCl}_{3}$.

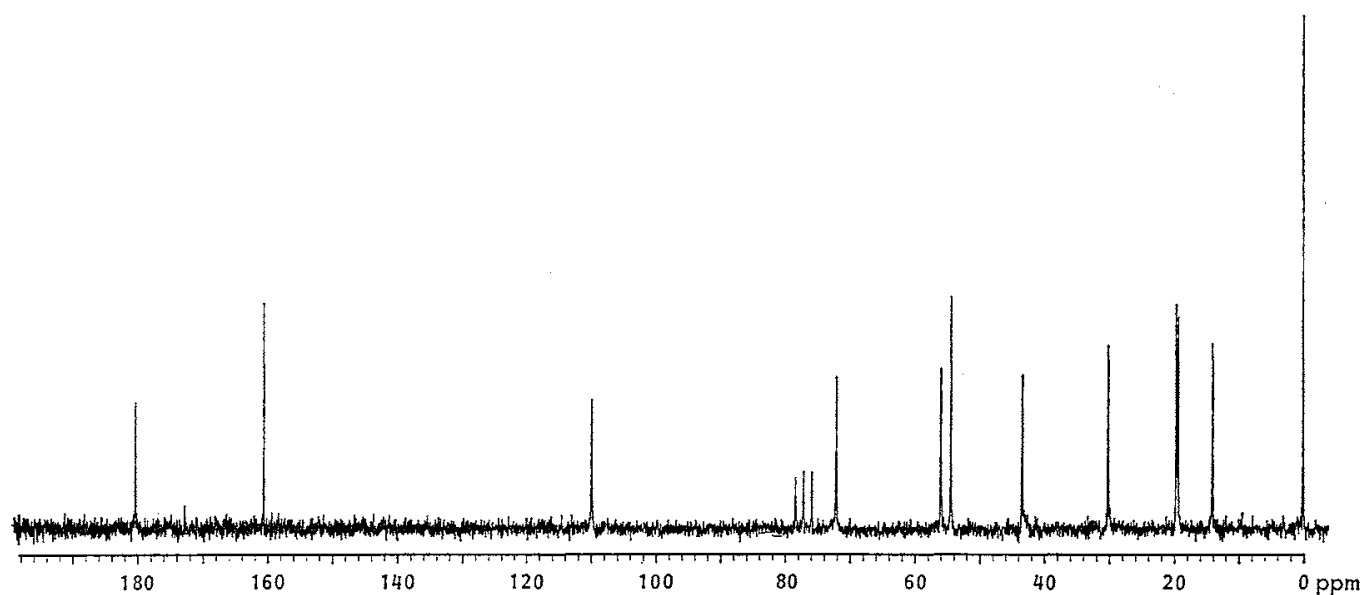

aqueous layer obtained in this way was adjusted

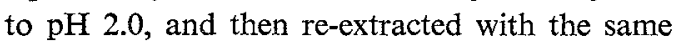
volume of EtOAc. The final extract was dried over $\mathrm{Na}_{2} \mathrm{SO}_{4}$ and concentrated under reduced pressure. The residue dissolved in $200 \mathrm{ml}$ of a mixture of EtOAc and $\mathrm{CHCl}_{3}(1: 1)$ was subjected to chromatography on a column of Sephadex LH-20 (2 liters) with the same solvent mixture. Fractions 1 and 2 were further purified by rechromatography on Sephadex LH-20 using a solvent system composed of $\mathrm{CHCl}_{3}$ - EtOAc -

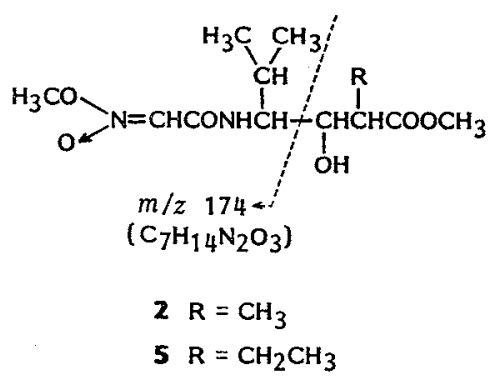




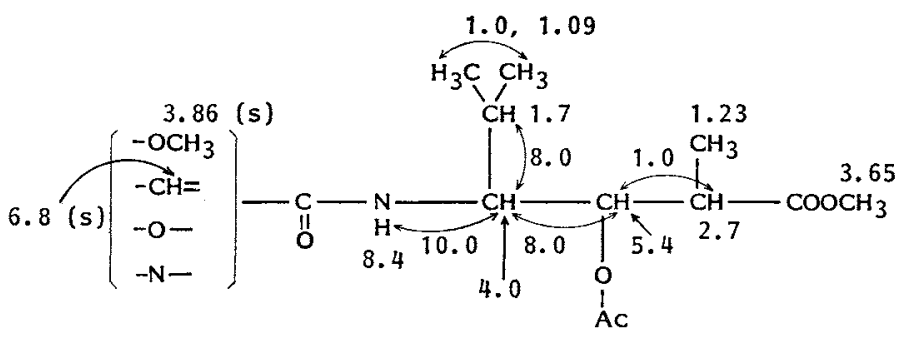

$n$-hexane $(2: 1: 1)$ to yield $200 \mathrm{mg}$ of nitracidomycin $\mathrm{B}(\mathbf{1 b})$ and $2.5 \mathrm{~g}$ of nitracidomycin A (1a), respectively.

Nitracidomycin A (1a) showed UV max at $251 \mathrm{~nm}(\varepsilon 5,100$ in $\mathrm{MeOH})$ and $[\alpha]_{\mathrm{D}}^{25}-31.9^{\circ}$ (c 2.0, $\mathrm{CHCl}_{3}$ ). IR and ${ }^{1} \mathrm{H}$ and ${ }^{13} \mathrm{C}$ NMR spectra of 1a are shown in Figs. 1, 2 and 3 . Reaction of $1 \mathrm{a}$ with diazomethane gave 2.2 was deduced a monomethyl ester of $\mathbf{1 a}$ from the analysis of ${ }^{1} \mathrm{H}$ NMR spectrum. Elemental analysis of 2 gave $\mathrm{C} 49.91, \mathrm{H} 7.50, \mathrm{~N} 9.53 \%$ (C 49.65, H 7.64, N 9.65, calcd for $\mathrm{C}_{12} \mathrm{H}_{22} \mathrm{~N}_{2} \mathrm{O}_{8}$ ). The high resolution mass spectrum (HR-MS) of 2 showed the molecular ion peak at $m / z 291.1538$ $\left(\mathrm{C}_{12} \mathrm{H}_{23} \mathrm{~N}_{2} \mathrm{O}_{8}, \mathrm{M}+\mathrm{H}^{+}\right)$and base ion peak at $\mathrm{m} / \mathrm{z}$ $174.0965\left(\mathrm{C}_{7} \mathrm{H}_{14} \mathrm{~N}_{2} \mathrm{O}_{3}\right)$. Acetylation of 2 with acetic anhydride in pyridine gave a monoacetate (3); $\mathrm{C}_{14} \mathrm{H}_{25} \mathrm{~N}_{2} \mathrm{O}_{7}, m / z 333\left(\mathrm{M}+\mathrm{H}^{+}\right)$. The detailed analyses of ${ }^{1} \mathrm{H}$ and ${ }^{13} \mathrm{C}$ NMR spectra of 2 and 3 in $\mathrm{CDCl}_{3}$ indicated the assigned partial structure of 3 .

The UV absorption maximum at $251 \mathrm{~nm}$ in the structure of nitracidomycin A suggested a nitronic acid moiety. Further evidence for a nitronic acid moiety was obtained as follows: Hydrogenation of $1 \mathbf{a}$ with platinum oxide in $\mathrm{MeOH}$ gave a peptide (4). Hydrolysis of 4 with $12 \mathrm{~N} \mathrm{HCl}-\mathrm{AcOH}(1: 1)$ gave glycine and a new amino acid, 4-amino-3-hydroxy-2,5dimethylhexanoic acid (AHDMHA) by amino acid analysis. This new hydroxy amino acid, AHDMHA, $\mathrm{C}_{8} \mathrm{H}_{17} \mathrm{NO}_{3}$, was also obtained by hydrolysis of 1a under the same condition as mentioned above, followed by column chromatography on Sephadex G-10 developed with $\mathrm{BuOH}-\mathrm{AcOH}-\mathrm{H}_{2} \mathrm{O}$ (4:1:5, upper layer). The ${ }^{1} \mathrm{H}$ NMR spectrum of AHDMHA displayed three doublet methyl protons at $\delta 0.80\left(\mathrm{CH}_{3}\right)$, $0.86\left(\mathrm{CH}_{3}\right)$ and $1.01\left(\mathrm{CH}_{3}\right)$ and four methine protons at $1.90(\delta), 2.35(\alpha), 2.93(\gamma)$ and $3.63(\beta)$, respectively.<smiles>CC(C)C(O)C(NC(=O)CN)C(C)C(=O)O</smiles>

These assignments strongly supported the partial structure described above and the structure of nitracidomycin $\mathrm{A}$ as $\mathbf{1 a}$.

Nitracidomycin B (1b) also gave monomethyl ester (5), $\mathrm{C}_{13} \mathrm{H}_{25} \mathrm{~N}_{2} \mathrm{O}_{3}, m / z \quad 305\left(\mathrm{M}+\mathrm{H}^{+}\right)$, by treatment with diazomethane. In the ${ }^{1} \mathrm{H}$ NMR spectrum of $\mathbf{5}$, a newly appeared ethyl signal was detected at $0.87\left(\mathrm{t}, \mathrm{CH}_{3}\right)$, and $1.7\left(\mathrm{~m}, \mathrm{CH}_{2}\right)$, but doublet at $1.20 \mathrm{ppm}$ of $\alpha$-methyl signal derived from the structure 2 was disappeared. This result indicated that nitracidomycin $B$ has an ethyl group instead of an $\alpha$-methyl group in nitracidomycin A. Further structural evidence was obtained from the mass spectrometry. In the mass spectrum of $\mathbf{5}$, the base ion peak at $\mathrm{m} / \mathrm{z}$ 174 appeared as same as 2 . This fragment ion supported the presence of the same moiety in 2 and 5.

Therefore, the structure of nitracidomycin B was determined as $\mathbf{1 b}$. The structural characteristics of nitracidomycins $\mathbf{A}$ and $\mathbf{B}$ include the $O$-methyl nitronic acid moiety reported as a constituent of enteromycin ${ }^{2)}$, enteromycin carboxamide ${ }^{3)}, \mathrm{U}-22956^{2)}$, YN-0165J-A ${ }^{4)}$, seligo$\operatorname{cidin}^{5)}$ and thermycetin ${ }^{6)}$, and the presence of 4-amino-3-hydroxy acid moiety such as 4amino-3-hydroxy-6-methylheptanoic acid in pepstatin ${ }^{7)}$, and 4-amino-3-hydroxy-2-methylpentanoic acid in bleomycin ${ }^{8)}$. The configurations of $\mathbf{1 a}$ and $\mathbf{1 b}$ are now under investigation.

Antimicrobial activity of nitracidomycin A was determined by conventional agar-dilution method as shown in Table 1. It is moderately 
Table 1. Antimicrobial activity of nitracidomycin A.

\begin{tabular}{lcc}
\hline \multicolumn{1}{c}{ Test organism } & Medium & MIC $(\mu \mathrm{g} / \mathrm{ml})$ \\
\hline Staphylococcus aureus FDA 209P JC-1 & A & 50 \\
S. aureus SANK 71075 & A & 50 \\
S. epidermidis SANK 71575 & A & 50 \\
Bacillus subtilis PCI 219 & $\mathrm{A}$ & 50 \\
Enterococcus faecalis SANK 71478 & $\mathrm{A}$ & 25 \\
Micrococcus luteus PCI 1001 & $\mathrm{A}$ & 50 \\
Escherichia coli NIHJ JC-2 & $\mathrm{A}$ & $>200$ \\
Pseudomonas aeruginosa SANK 73575 & $\mathrm{A}$ & $>200$ \\
Klebsiella pneumoniae SANK 74975 & $\mathrm{A}$ & $>200$ \\
Serratia marcescens SANK 73060 & $\mathrm{A}$ & $>200$ \\
Bacteroides fragilis SANK 71176 & $\mathrm{B}$ & 50 \\
B. fragilis SANK 70478 & $\mathrm{B}$ & 100 \\
B. fragilis SANK 70678 & $\mathrm{B}$ & 200 \\
B. fragilis SANK 70878 & $\mathrm{B}$ & 200 \\
\hline
\end{tabular}

Medium A: Mueller-Hinton agar (Difco).

Medium B: GAM agar (Nissui).

Inoculum size: $10^{6}$ cells $/ \mathrm{ml}$.

active against Gram-positive and Gram-negative bacteria, especially against Enterococcus faecalis and $B$. fragilis. Antimicrobial activity of nitracidomycin B was very similar to that of nitracidomycin A determined by conventional paper-disc agar diffusion assay.

Nitracidomycins $\mathbf{A}$ and $\mathbf{B}$ were also able to induce spheroplast formation of Gram-negative bacteria such as Proteus mirabilis SANK 71873 at a concentration equivalent to the MIC.

The acute toxicity $\left(\mathrm{LD}_{50}\right)$ of nitracidomycin $\mathrm{A}$ in mice was $150 \mathrm{mg} / \mathrm{kg}$ by intravenous administration.

\section{MichiKo TAKEUCHI MASATOSHI INUKAI RYUZO ENOKITA TOSHIO TAKATSU YASUYUKI TAKamatsU SHujI TAKaHashi Tatsuo Haneishi ${ }^{\dagger}$}

Fermentation Research Laboratories, Sankyo Co., Ltd., 1-2-58 Hiromachi, Shinagawa-ku, Tokyo 140, Japan 'Technical Licensing Department, Sankyo Co., Ltd., 2-7-12 Ginza, Chuo-ku, Tokyo 104, Japan

(Received September 26, 1988)

\section{References}

1) Haneishi, T.; S. Takahashi, M. InukaI, Y. Itoh, T. Takatsu, R. Enokita, A. Torikata \& S. IWADo (Sankyo): Nitracidomycins $A$ and B. Jpn. Kokai 15694 ('86), Jan. 23, 1986

2) Mizuno, K.: Structure of enteromycin. IV. Bull. Chem. Soc. Jpn. 34: 1633 1639, 1961

3) Mitscher, L. A.; W. McCrae \& S. E. DeVoe: The structural characterization of enteromycin carboxamide. A new streptomycete antibiotic. Tetrahedron 21: $267 \sim 271,1965$

4) Imai, H.; K. Suzuki, S. Takamura, S. Kadota \& M. IWANAm: A new enteromycin group antibiotic, YN-0165J-A produced by Streptomyces sp. J. Antibiotics 39: 601 602, 1986

5) Wiley, D. F.; R. R. Herr, F. A. MacKellar \& A.D. Argoudelis: Three chemically related metabolites of Streptomyces. II. Structural studies. J. Org. Chem. 30: 2330 2334, 1965

6) Miller, B. M. \& I. Putter (Merck): Thermycetin and method for preparation. U.S. 3,102,076 ('63), Aug. 27, 1963

7) Umfzawa, H.; T. Aoyagi, H. Morishima, M. Matsuzaki, M. Hamada \& T. Takeuchi: Pepstatin, a new pepsin inhibitor produced by actinomycetes. J. Antibiotics 23: 259 262, 1970

8) Takita, T.; Y. Muraoka, K. Maeda \& H. UMEZAWA: Chemical studies on bleomycins. I. The acid hydrolysis products of bleomycin A $_{2}$. J. Antibiotics 21: 79 80, 1968 